\title{
Lignocaine: a new technique for intravenous administration
}

\author{
RICHARD A. LEVY, YZHAR CHARUZI, AND WILLIAM J. MANDEL 1 \\ From the Department of Cardiology, Cedars-Sinai Medical Center, Los Angeles, California, U.S.A.
}

Current practices of intravenous lignocaine administration may result in a significant drop in blood level between the peak serum level from the initial bolus and the subsequent steady state from the constant infusion. This can cause a significant interval when plasma lignocaine levels are less than therapeutic, and ventricular ectopy may occur. To eliminate this subtherapeutic interval, a new therapeutic approach was devised.

Seven patients were studied who had no evidence of congestive heart failure or liver disease. Lignocaine was infused at a rate of $25 \mathrm{mg} / \mathrm{min}$; infusion dosages were selected by patient weight. The above therapeutic regimen eliminated the subtherapeutic hiatus and did not result in clinical toxicity. Therefore, this new infusion technique has significant clinical advantages in patients who require therapy with intravenous lignocaine.

Intravenous lignocaine has been shown to be an effective drug for the treatment of ventricular arrhythmias in the coronary care unit setting (Gianelly et al., 1967; Jewitt et al., 1968; Harrison and Collinsworth, 1974; Lie et al., 1974). The usual method of administration is an initial 50 $100 \mathrm{mg}$ bolus ( 1 to $2 \mathrm{mg} / \mathrm{kg}$ ) followed by a continuous 1 to $4 \mathrm{mg} / \mathrm{min}$ infusion (Gianelly et al., 1967; Collinsworth et al., 1974). These current methods of lignocaine administration may result in a significant period of time during which the lignocaine serum level is below the therapeutic range (Aps et al., 1976; Greenblatt et al., 1976). This is because of a combination of rapid fall-off in serum levels from the bolus and a slow build-up in serum levels from the infusion. Inadequate antiarrhythmic protection might then allow for a return of ventricular ectopy. The concept of a subtherapeutic hiatus in lignocaine therapy is of substantial clinical importance especially in the light of studies such as those of Lie et al. (1974). These workers have emphasised the efficacy of prophylactic lignocaine in the prevention of primary ventricular fibrillation in the setting of acute myocardial infarction.

The purpose of this study was to design a clinically usable method to eliminate this phenomenon of a therapeutic 'hiatus' secondary to subtherapeutic lignocaine serum levels.

${ }^{1}$ Milly Factor Clinical Investigator of the Western Cardiac Foundation.

Received for publication 10 January 1977

\section{Methods}

Seven patients were randomly selected from our cardiac care unit for study. These included 6 men and 1 woman, ages 40 to 65 , and weighing between 59.4 and $125.6 \mathrm{~kg}$. These were patients with either documented acute myocardial infarction (based on electrocardiographic criteria and appropriate increases in serum enzymes), preinfarction angina or proven ventricular ectopy, excluding ventricular tachycardia. Patients with significant congestive heart failure, liver disease, complete atrioventricular block, or persistent bradycardia were excluded from the study. Detailed informed consent was obtained.

An intravenous infusion of lignocaine at a rate of $25 \mathrm{mg} / \mathrm{min}$ was administered until a total dose of $200 \mathrm{mg}$ was given for those patients weighing less than $68 \mathrm{~kg}, 250 \mathrm{mg}$ for those between 68 and $90 \mathrm{~kg}$, and $300 \mathrm{mg}$ for those over $90 \mathrm{~kg}$. Upon completion of the initial dose, a constant infusion of lignocaine was immediately begun using an infusion pump ${ }^{2}$ at a rate of $20 \mu \mathrm{g} / \mathrm{min}$ for those between 68 and $90 \mathrm{~kg}$, and $30 \mu \mathrm{g} / \mathrm{min}$ for patients over $90 \mathrm{~kg}$; the infusion ran continuously throughout the $6 \frac{1}{2}$ hour study period.

In all patients, serum lignocaine levels were determined at $0,1,3,5,7,10,15,20,25,30,45$, 60 . and 90 minutes after completion of the initial infusion (Keenaghan, 1968). ${ }^{3}$ Blood samples were

2IVAC Corp., San Diego, California.

${ }^{3}$ Kindly performed by Astra Pharmaceutical Laboratories, Worchester, Massachusetts. 
then collected hourly for 5 or more hours. All samples were collected via a 16 or 18 gauge indwelling angiocatheter placed in the arm opposite the infusion site.

\section{Results}

The mean values and their respective standard errors for all patients throughout the entire study period are plotted in the Fig. At no time did the mean values fall below $1.4 \mathrm{mg} / 1$ or exceed $6.5 \mathrm{mg} / 1$. In 5 of 6 patients, blood levels consistently exceeded the therapeutic minimum at each point in the study; in the 5th patient, a transient drop was observed at 30 minutes. The minimum serum concentrations were observed at the 30 to 60 minute period after the initial bolus infusion. In the 2 patients who were continuously monitored, ectopic ventricular activity was completely abolished. Three patients experienced transient dizziness at the completion of the bolus infusion. One of these patients had symptomatology at a time when the highest blood level $(6.5 \mathrm{mg} / \mathrm{l})$ was observed. No patients experienced convulsions, hallucinations, tremors, bradycardia, hypotension, or heart block throughout the study period.

\section{Discussion}

Lignocaine pharmacokinetics can be explained as an equilibration between a central vascular and peripheral extravascular compartment (Boyes et al., 1971; Rowland et al., 1971). An intravenous bolus injection rapidly peaks within 1 to 2 minutes (Gianelly et al., 1967) and the pharmacological half-life averages 10 to 15 minutes (Rowland et al., 1971 ; Boyes et al., 1971). In contrast the elimination half-life ranges between 87 and 108 minutes (Rowland et al., 1971; Collinsworth et al., 1974). The exponential decay seen during the elimination phase relates to initial hepatic metabolism and rapid shifts between the central and peripheral compartment (Stenson et al., 1971); the longer plasma halflife is dependent on equilibration between peripheral and central compartments (Rowland et al., 1971). Thus, the serum level is determined by the effective volume of distribution, rate of administration and its diffusion into tissue and extracellular compartments.

Lignocaine is primarily metabolized by hepatic microsomal enzymes (Stenson et al., 1971; Harrison and Collinsworth, 1974); metabolism is directly proportional to hepatic blood flow (Stenson et al., 1971). In reduced cardiac output states, hepatic blood flow is generally decreased and the effective volume of distribution of the drug is also altered thus promoting higher blood levels at any rate of constant infusion (Stenson et al., 1971; Thomson et al., 1973). Therefore, patients with coexisting heart failure and/or liver disease will require a decreased constant infusion of lignocaine (Thomson et al., 1973). Excretion of lignocaine can be enhanced in a maximally acid urine though renal clearance accounts for no more than 20 per cent of the total body clearance (Thomson et al., 1973).

Therapeutic minimum and maximum serum lignocaine levels have been established; 80 per cent of patients who will suppress ventricular ectopy with lignocaine will suppress with serum levels between 1.4 and $5.5 \mu \mathrm{g} / \mathrm{l}$ (Gianelly et al., 1967; Collinsworth et al., 1974). The therapeutic maximum has generally been accepted at $5.5 \mu \mathrm{g} / \mathrm{ml}$ (Gianelly et al., 1967; Jewitt et al., 1968) though Alderman et al. (1974) suggested that the maximum should be extended to $6.0 \mu \mathrm{g} / \mathrm{ml}$. The cardiovascular side effects such as hypotension and heart block tend to occur after a large bolus administration which results in clearly toxic blood levels.

Conventional lignocaine administration includes

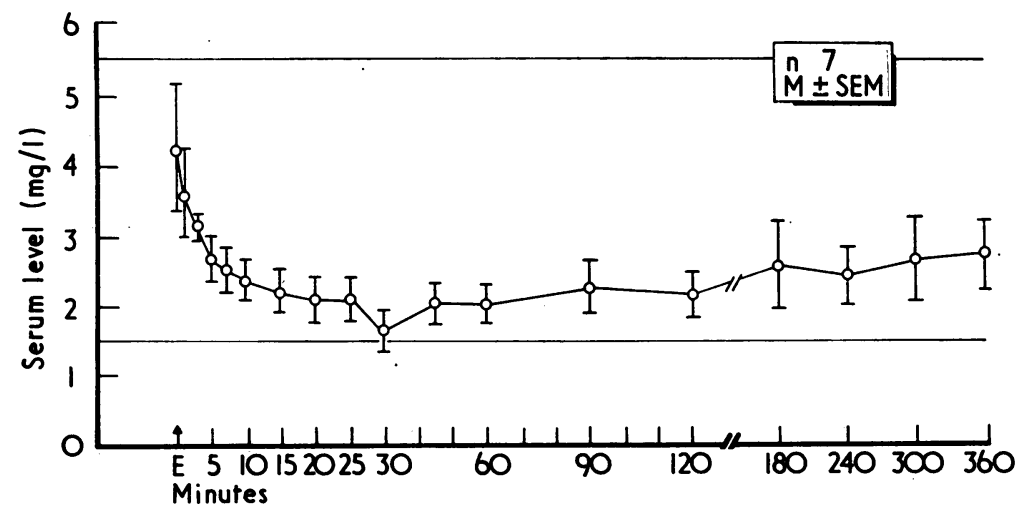

Effect of infusion technique on serial serum lignocaine levels in 7 patients. The horizontal lines identify the reported therapeutic range for lignocaine. The end of the initial high dose infusion of lignocaine is signified by $\boldsymbol{E}$. 
both an initial bolus and a constant infusion which theoretically accounts for the rapid central deactivation and the slower tissue equilibration. In this fashion, therapeutic levels are rapidly achieved rather than waiting at least 1 to 2 hours for a constant infusion alone to achieve therapeutic serum levels (Rowland et al., 1971). Collinsworth et al. (1974) recommend, in patients with varied cardiac output and hepatic function, that an initial $2 \mathrm{mg} / \mathrm{kg}$ bolus should provide therapeutic concentrations of lignocaine at all times if followed by a $55 \mu \mathrm{g} / \mathrm{ml}$ constant infusion.

However, results from our own institution (Bassan et al., 1974) show that using the standard combined $1 \mathrm{mg} / \mathrm{kg}$ initial bolus and weight-related constant infusion, a significant drop in plasma levels to less than 90 per cent of peak serum concentrations will occur 20 to 30 minutes after starting the infusion. Moreover, peak steady state levels are not achieved until at least 6 hours after onset of infusion (Bassan et al., 1974). The therapeutic dilemma is, therefore, to maintain adequate serum levels while the bolus is rapidly being degraded and the constant infusion is slowly increasing serum levels. Using our technique of large dose initial bolus, we achieve consistently therapeutic lignocaine levels at all points in the study period. After the rapid 10 to 15 minute exponential fall-off, serum values are basically constant during the 20 to 60 minute period and then gradually approach steady state concentrations. The chance for recurrent ventricular ectopy from inadequate serum levels is, therefore, significantly lessened.

Other recent studies (Goldreyer and Wyman, 1975; Jelliffe et al., 1975; Aps et al., 1976) have suggested other forms of lignocaine administration to avoid the potential pitfall of a subtherapeutic hiatus. These methods require either serial intravenous doses or complicated computer controlled infusion systems. Our present study has the advantage of simplicity yet raises the subtherapeutic hiatus.

Nevertheless, a final note of caution should be issued with regard to this or any other therapeutic regimen for intravenous lignocaine administration. The presence of overt or occult left ventricular failure may predispose to the development of lignocaine intoxication at a low dosage schedule. Therefore, therapeutic regimens whatever their design should be tempered in this clinical setting.

In summary, our present studies have shown that a large initial bolus infusion coupled with a constant infusion provides continuous therapeutic levels of lignocaine. Furthermore, high dose lignocaine administered in this manner is not associated with toxic blood levels. Therefore, we believe that this method offers significant therapeutic advantages over currently accepted modes of lignocaine administration.

\section{References}

Alderman, E. L., Kerber, R. E., and Harrison, D. C. (1974). Evaluation of lidocaine resistance in man using intermittent large-dose infusion techniques. American fournal of Cardio$\log y, 34,342-349$.

Aps, C., Bell, J. A., Jenkins, B. S., Poole-Wilson, P. A., and Reynolds, F. (1976). Logical approach to lignocaine therapy. British Medical fournal, 1, 13-15.

Bassan, M. B., Weinstein, S. R., and Mandel, W. J. (1974). Use of lidocaine by continuous infusion. American Heart fournal, 87, 302-303.

Boyes, R. N., Scott, D. B., Jebson, P. J., Godman, M. J., and Julian, D. G. (1971). Pharmacokinetics of lidocaine in man. Clinical Pharmacology and Therapeutics, 12, 105-116.

Collinsworth, K. A., Kalman, S. M., and Harrison, D. C. (1974). Clinical pharmacology of lidocaine as an antiarrhythmic drug. Circulation, 50, 1217-1230.

Gianelly, R., Von der Groeben, J. O., Spivack, A. P., and Harrison, D. C. (1967). Effect of lidocaine on ventricular arrhythmias in patients with coronary heart disease. New England fournal of Medicine, 277, 1215-1219.

Goldreyer, B. N., and Wyman, M. G. (1975). High dose of lidocaine in acute myocardial infarction (abstract). American College of Physicians, April 1975, San Francisco.

Greenblatt, D. J., Bolognini, V., Koch-Weser, J., and Harmatz, J. S. (1976). Pharmacokinetic approach to the clinical use of lidocaine intravenously. fournal of the American Medical Association, 236, 273-277.

Harrison, D. C., and Collinsworth, K. A. (1974). Antiarrhythmic effects of lidocaine. In Annual Review of Medicine, 25, p. 143. Year Book Medical Publishers, Chicago.

Jelliffe, R., Goicoechea, F., Tuey, D., Wyman, M., Rodman, J., and Goldreyer, B. (1975). An improved computer program for lidocaine infusion regimens. Clinical Research, 23, $125 \mathrm{~A}$.

Jewitt, D. E., Kishon, Y., and Thomas, M. (1968). Lignocaine in the management of arrhythmias after acute myocardial infarction. Lancet, 1, 266-270.

Keenaghan, J. B. (1968). The determination of lidocaine and prilocaine in whole blood by gas chromatography. Anesthesiology, 29, 110-112.

Lie, K. E., Wellens, H. J. J., van Capelle, F. J., and Durrer, D. (1974). Lidocaine in the prevention of primary ventricular fibrillation. New England fournal of Medicine, 291, 1324-1326.

Rowland, M., Thomson, P. D., Guichard, A., and Melman, K. (1971). Disposition kinetics of lidocaine in normal subjects. Annals of the New York Academy of Sciences, 179, 383-398.

Stenson, R. E., Constantino, R. T., and Harrison, D. C. (1971). Interrelationships of hepatic blood flow, cardiac output, and blood levels of lidocaine in man. Circulation, 43, 205-211.

Thomson, P. D., Melmon, K. L., Richardson, J. A., Cohn, K., Steinbrunn, W., Cudihee, R., and Rowland, M. (1973). Lidocaine pharmacokinetics in advanced heart failure, liver disease and renal failure in humans. Annals of Internal Medicine, 78, 499-508.

Requests for reprints to Publication Office, CedarsSinai Medical Center, Department of Cardiology, 8700 Beverly Blvd., Los Angeles, California 90048, U.S.A. 